\title{
Forest Biomass Utilization for Biofuels and Bioproducts
}

\author{
Jingxin Wang, ${ }^{1}$ Shirong Liu, ${ }^{2}$ Tom Gallagher, ${ }^{3}$ David DeVallance, ${ }^{1}$ and Levente Denes ${ }^{4}$ \\ ${ }^{1}$ Wood Science and Technology, Division of Forestry and Natural Resources, West Virginia University, \\ Morgantown, WV 26505, USA \\ ${ }^{2}$ Forest Ecology and Hydrology, Chinese Academy of Forestry, Beijing 100091, China \\ ${ }^{3}$ Forest Operations, School of Forestry and Wildlife Sciences, Auburn University, Auburn, AL 36849-5418, USA \\ ${ }^{4}$ Institute of Product Design and Manufacturing, University of West Hungary, Sopron, Hungary
}

Correspondence should be addressed to Jingxin Wang, jxwang@wvu.edu

Received 1 July 2012; Accepted 1 July 2012

Copyright () 2012 Jingxin Wang et al. This is an open access article distributed under the Creative Commons Attribution License, which permits unrestricted use, distribution, and reproduction in any medium, provided the original work is properly cited.

Demand for biofuels and bioproducts in the world is growing due to shortage of fossil fuels and carbon footprint. Currently, forest biomass, the most abundant naturally occurring resources, is a potentially important feedstock for the production of various forms of biofuels and bioproducts. The benefits of using biomass as feedstock include reduction of the use of nonrenewable fuels, less dependency on fossil fuels, stabilization of income in rural areas, and reduced carbon emissions to the atmosphere. However, there are still some issues for management and harvesting of forest biomass and commercialization of biofuels and bioproducts from it. Knowledge and understanding of these issues have led to the development of technology and policies. In this special issue, we have invited ten papers that will stimulate the continuing efforts to understand the forest biomass management, site and environmental impacts, processing, handling, and logistics, and preprocessing and conversion technologies of biofuels and bioproducts from forest biomass as well as applications of biofuels and bioproducts.

One of the papers of this special issue reviews the recent technologies on co-gasification of coal and biomass using different types of gasifiers under various sets of operating conditions. The influences of cogasification of upstream and downstream processing are also discussed. A paper evaluates the operational performance and cost of a whole-tree biomass operation. The productivity and cost of the integrated system are examined using a standard time motion study method. Of these paper, one provides an overview of the current forest biomass estimation using both Landsat Thematic Mapper and LiDAR data. A case study was conducted to illustrate the applications of these two methods and related uncertainty analyses.

A paper addresses environmental effects of growing feedstocks on rodent community and populations. The results indicate that the planting of switchgrass has speciesspecific effects on rodents. There is a paper which evaluates biomass production, $\mathrm{C}$ and $\mathrm{N}$ allocation patterns in Robinia pseudoacacia stands between shoot, stump, coarse, and fine roots. Its results show a high potential for $\mathrm{C}$ and $\mathrm{N}$ storage of $R$. pseudoacacia. The paper that discusses the potency of converting biomass into biomethanol at forest management units through three forest management practices shows that a large amount of net carbon emission can be avoided if biomass can be converted to biofuel.

There is a paper included in this special issue that presents a study on production of 10 woody biomass species. It tries to analyze the structure of 10 woody species in semiarid zones of northeastern Mexico. The paper indicates that high volume of biomass could be yielded by most of the species with great energetic potentials when used as firewood or charcoal. Another one evaluates the impacts of some feedstock and operational factors on cost effectiveness of producing chips and pellets. It indicates that small-scale low-temperature drying and foliage and bark separation are essential to reduce pellet production cost. A paper analyzes the stakeholders' opinions about biomass harvesting guidelines (BHGs) through 60 semistructured interviews with key participants in the forest business sector in North Carolina. The results suggest BHGs need to be better justified for practitioners to protect forest health and reduce 
unnecessary costs. Finally, a paper presents the spatial and temporal dynamics of tree fine roots in six common boreal forests in Eastern Sweden. The amount of live and dead fine roots in terms of dry weight was estimated. The results show a high accumulation of carbon from dead tree fine root.

Jingxin Wang Shirong Liu Tom Gallagher David DeVallance Levente Denes 

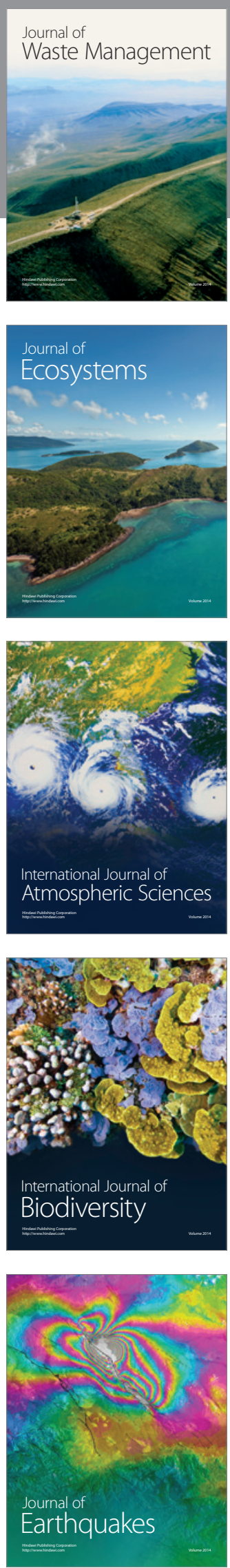
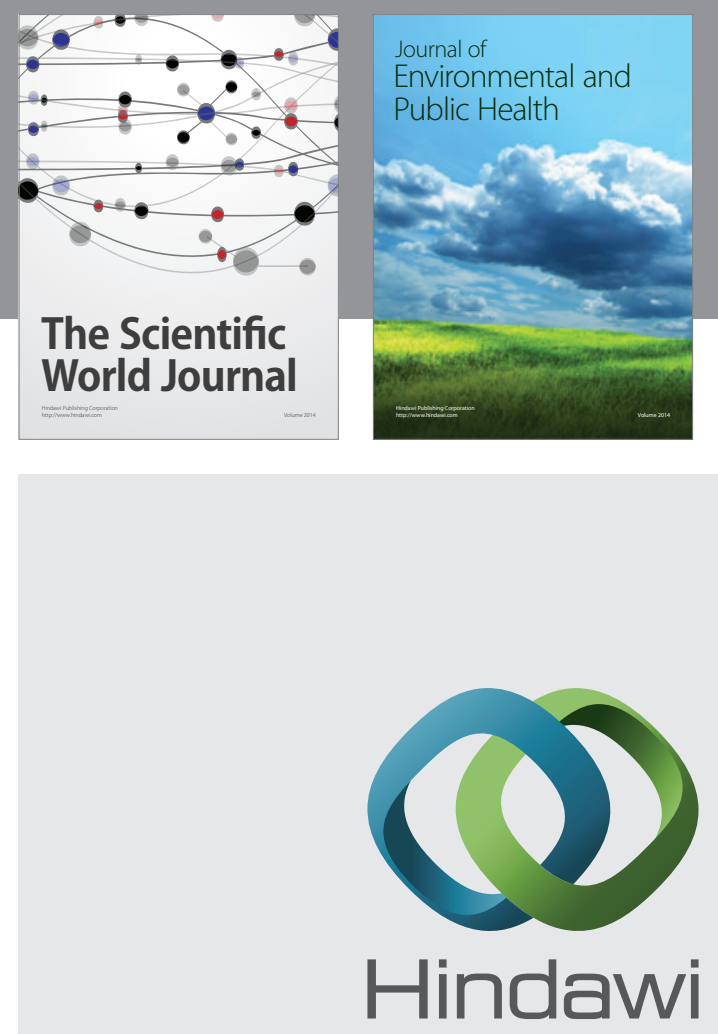

Submit your manuscripts at

http://www.hindawi.com
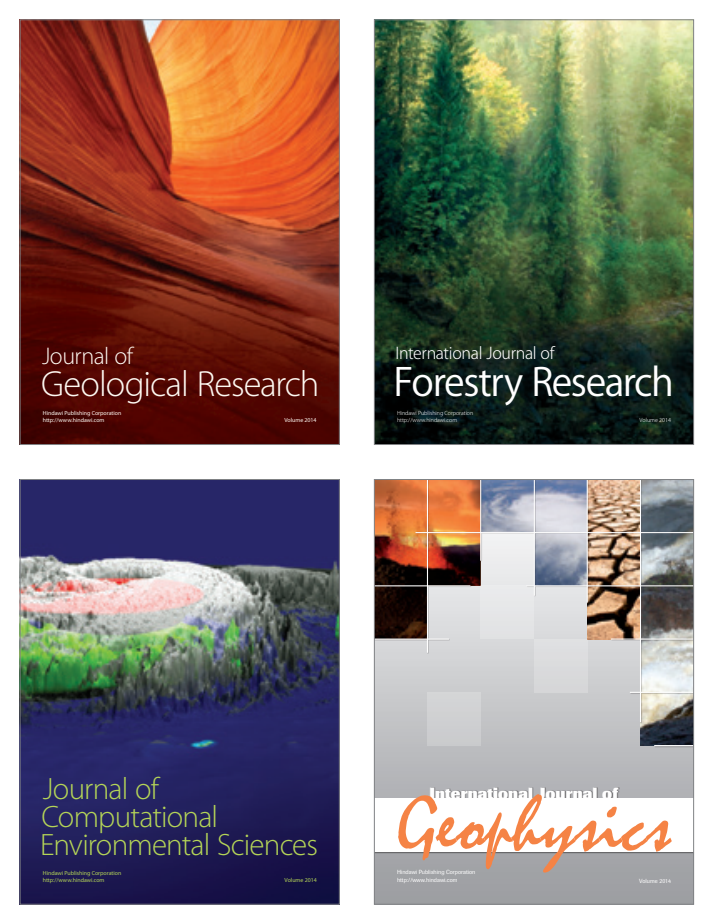
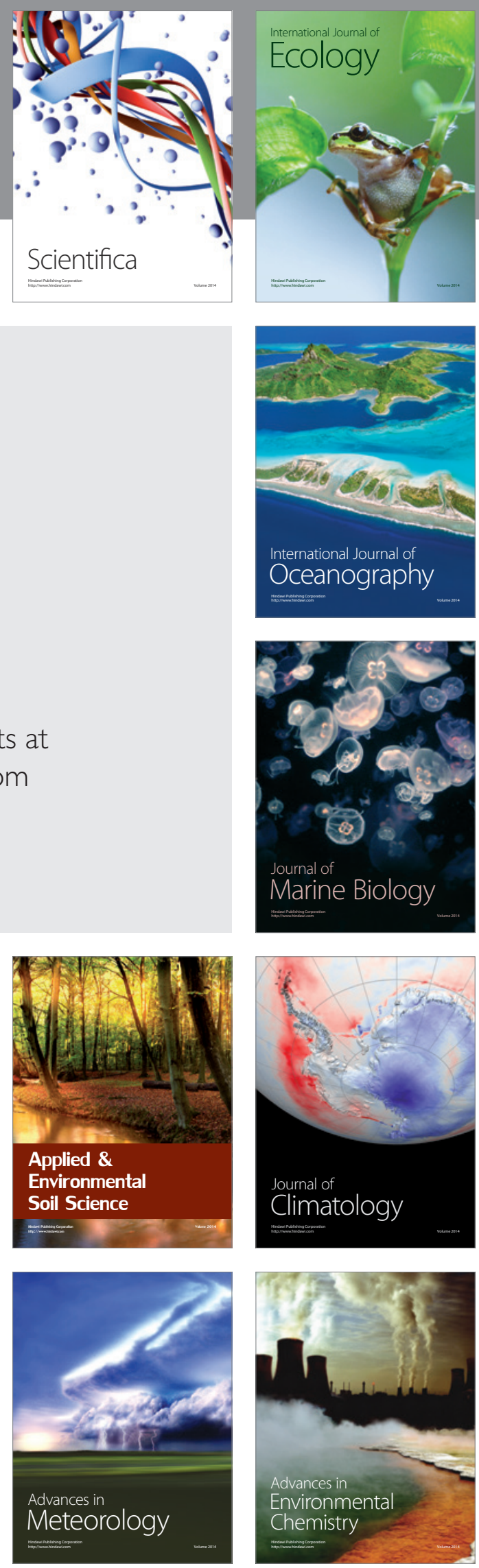